\title{
Cocaine-induced psychomotor activity is associated with its ability to induce c-fos mRNA expression in the subthalamic nucleus: effects of dose and repeated treatment
}

\author{
Jason M. Uslaner, Hans S. Crombag, Susan M. Ferguson and Terry E. Robinson \\ Biopsychology and Neuroscience Programs, Department of Psychology, The University of Michigan, East Hall, 525 E. University St., \\ Ann Arbor, MI 48019-1109, USA
}

Keywords: caudate-putamen, enkephalin, rat, sensitization, substance $\mathrm{P}$

\begin{abstract}
Factors that modulate the psychomotor activating effects of amphetamine and cocaine, such as environmental novelty and dose, also regulate the ability of these drugs to induce c-fos mRNA expression in the subthalamic nucleus (STN). We hypothesized therefore that engagement of the STN may be important for stimulant-induced psychomotor activation. To further test this hypothesis we examined whether repeated treatment with cocaine, which enhances its psychomotor activating effects (i.e. produces behavioural sensitization), also enhances its ability to induce c-fos expression in the STN. In addition, given that STN activity is thought to be influenced by preproenkephalin mRNA-containing ( $E N K+$ ) neurons in the caudate-putamen, we also examined whether repeated cocaine treatment alters c-fos expression in ENK+ cells. We report that: (i) cocaine pretreatment enhances the ability of a cocaine challenge to induce cfos mRNA expression in the STN, and this effect is most robust at challenge doses where behavioural sensitization is observed; (ii) the ability of cocaine to induce c-fos in the STN is independent of the ability of cocaine to engage ENK+ cells. These results support the idea that the STN is involved in stimulant-induced psychomotor activation and sensitization, but suggest that stimulant-induced engagement of the STN is not dependent on ENK+ cells in the caudate-putamen. These findings may have implications concerning the neurobiological mechanisms underlying the behavioural effects of psychostimulant drugs.
\end{abstract}

\section{Introduction}

Over the past several decades much research has sought to identify the neural systems that mediate the behavioural effects of psychostimulant drugs, such as amphetamine and cocaine. It is now clear that many of their behavioural effects are due in large part to their ability to increase dopamine neurotransmission in the nucleus accumbens and caudateputamen $(\mathrm{CPu})$. On the other hand, very little is known about the importance of striatofugal targets. One such structure, the subthalamic nucleus (STN), is a principal component of the so-called indirect pathway', a pathway which arises from enkephalin-containing cells in the $\mathrm{CPu}(\mathrm{ENK}+$ cells) (Albin et al., 1989).

We have recently found that factors which influence the ability of psychostimulants to produce psychomotor activation, such as environmental context and dose, also modulate their ability to induce c-fos mRNA expression in the STN. Specifically, low to moderate doses of amphetamine or cocaine given in a novel test environment induce more robust psychomotor activation and c-fos expression in the STN than when these doses are given in the home cage (Uslaner et al., 2001b; Ostrander et al., 2003; Uslaner et al., 2003). Higher doses of amphetamine, which produce robust psychomotor activation when given in either the home cage or a novel environment (Browman et al., 1998), induce robust c-fos expression in the STN independent of environmental context (Uslaner et al., 2003). Therefore, we hypothesized that

Correspondence: Dr Terry E. Robinson, as above.

E-mail: ter@umich.edu

Received 31 January 2003, revised 12 March 2003, accepted 13 March 2003 the ability of stimulant drugs to engage the STN may be important for their ability to produce psychomotor activation.

To further test this hypothesis we examined whether repeated treatment with cocaine ( 7 days with $15 \mathrm{mg} / \mathrm{kg} /$ day), which enhances its ability to produce psychomotor activation (i.e. behavioural sensitization), would also enhance its ability to induce c-fos expression in the STN. In addition, in order to examine whether ENK+ cells in the $\mathrm{CPu}$ (and presumably the indirect pathway) are involved in the ability of cocaine to engage the STN, we characterized the ability of cocaine pretreatment to modulate cocaine-induced c-fos expression in ENK+ cells in the $\mathrm{CPu}$, using dual in situ hybridization histochemistry.

Materials and methods

\section{Animals}

Seventy-three male Sprague-Dawley rats (Harlan, Indianapolis, IN, USA) weighing 200-250 g were housed individually in square clear plastic cages with pine shavings on the floor and food and water freely available. The room was kept at a constant temperature and humidity and was on a $14: 10$-h light : dark cycle (lights on at $07.00 \mathrm{~h}$ ). The animals were acclimated to the colony room for 7 days prior to any experimental manipulation. All experimental procedures were approved by the University of Michigan Committee on the Use and Care of Animals.

\section{Drugs}

Cocaine hydrochloride $(7.5,15$ or $30 \mathrm{mg} / \mathrm{mL})$ was dissolved in $0.9 \%$ saline and administered i.p. in a volume of $1 \mathrm{~mL} / \mathrm{kg}$. All drug weights refer to the weight of the salts. 


\section{Testing environment}

All rats were treated in clear rectangular tubs $(22 \times 45 \times 23 \mathrm{~cm})$, each of which contained a clear plastic insert in the centre of the cage $(6.5 \times 23 \times 23 \mathrm{~cm})$ forming a corridor through which rats could locomote. Three sets of infrared photocells were located along the length of the tub and were spaced $\approx 11.5 \mathrm{~cm}$ apart from one another. A break was counted each time a photo beam was interrupted.

\section{Testing procedures}

Each pretreatment day, rats were transported from their home cages, placed into the testing environment and left to habituate for $30 \mathrm{~min}$. The habituation period was used to attenuate the development of a conditioned response (Crombag et al., 2001). Following the habituation period, each rat received an i.p. injection of either saline or $15 \mathrm{mg} /$ $\mathrm{kg}$ of cocaine. Sixty minutes following the injection, the rats were returned to their home cages in the animal colony. All rats received saline or cocaine treatment for 7 consecutive days, after which they were left undisturbed in the animal colony room for a 3-week withdrawal period. Following the withdrawal period, saline- and cocainepretreated rats were brought back to the test environment, habituated for $30 \mathrm{~min}$ and then given a challenge injection of saline or 7.5, 15, or $30 \mathrm{mg} / \mathrm{kg}$ of cocaine ( $n=8-11 /$ group).

Fifty minutes after the challenge injection each rat was decapitated and the brain was removed and immediately frozen in isopentane $(-40$ to $-50{ }^{\circ} \mathrm{C}$ ). The 50 -min timepoint was chosen because it was used in previous studies and because it coincides with maximal c-fos mRNA expression (Badiani et al., 1998, 1999; Uslaner et al., 2001a; Uslaner et al., 2001b). The brains were stored in a $-70{ }^{\circ} \mathrm{C}$ freezer until they were sectioned. A cryostat was used to cut 10 - $\mu$ m-thick coronal sections at the level of the $\mathrm{CPu}$ and $\mathrm{STN}(\approx 0.8$ and $4 \mathrm{~mm}$ posterior to bregma, respectively). The sections were thaw-mounted onto slides coated with polylysine and stored at $-70^{\circ} \mathrm{C}$ until processing for in situ hybridization.

\section{In situ hybridization and quantification of $m R N A$}

All in situ hybridization methods were as described previously (Uslaner et al., 2001b) except that dual in situ hybridization was performed using ${ }^{35} \mathrm{~S}$-UTP- and ${ }^{35} \mathrm{~S}-\mathrm{CTP}$-labelled riboprobes for c-fos mRNA (680-mer; courtesy of Dr T. Curran), and digoxigenin-UTP-labelled riboprobes complimentary for preprotachykinin mRNA [substance P (SP)] or preproproenkephalin mRNA (567-mer and 693-mer, respectively; courtesy of Dr J. Douglass, Amgen, Thousand Oaks, CA, USA). The single in situ hybridization method was adapted from that described by Cullinan et al. (1995) and the double in situ hybridization method from that by Curran \& Watson (1995). Sections containing the STN were processed for single in situ hybridization using the riboprobe complementary to c-fos mRNA. Sections containing the $\mathrm{CPu}$ were processed for dual in situ hybridization using the riboprobe complementary to c-fos mRNA and preprotachykinin or preproenkephalin mRNA. Single-labelled sections were exposed to X-ray film (Kodak Biomax, MR) for $\approx 3$ days. Double-labelled sections were dipped in Ilford KD-5 emulsion (Polysciences) and stored at $4{ }^{\circ} \mathrm{C}$ ( $\approx 7$ days). After development (Kodak D-19), the slides were dehydrated in graded alcohols and coverslipped with Permount.

\section{Quantification}

Single-labelled sections were quantified as described previously (Badiani et al., 1998). Briefly, brain images were captured with a Sony CCD camera from the X-ray film, and semiquantitative analysis was performed on the digitized autoradiograms using National Institute of Health Image Software (NIH Image). Pixels were counted when the optical density values were at least $3.5 \mathrm{SD}$ above background value (background obtained from corpus callosum; macro written by Dr S. Campeau, University of Colorado, Boulder). Thus, the data are represented as relative integrated optical density in arbitrary units, which reflects both signal intensity and the number of pixels above background divided by total area (Badiani et al., 1998; Day et al., 2001). Adjacent sections were stained with Cresyl Violet to help with anatomical localization.

Double-labelled tissue from the $\mathrm{CPu}$ was quantified using a Leica microscope (Leitz DMR, Wetzler, Germany) at a total magnification of $200 \times$. Digoxigenin-labelled cells appeared as a purple precipitate in brightfield conditions, and a cell was considered positive only when it was a much darker hue of purple than background (background obtained from corpus callosum). ${ }^{35} \mathrm{~S}$-labelled cells appeared as densely packed silver grains in darkfield conditions, and a cell was considered positive only when the density of silver grains was clearly above background. The same criteria were used to analyse all slides, and the experimenter quantifying the tissue was blind to treatment conditions. We analysed a $500 \times 500-\mu \mathrm{m}$ portion of the dorsomedial and dorsolateral $\mathrm{CPu}$ in each hemisphere. There were no differences in cell counts between these areas, so they were combined. We examined these regions within the $\mathrm{CPu}$ because in previous studies we found that cocaine-induced c-fos expression was greatest in this area of the caudal CPu (Uslaner et al., 2001a).

\section{Controls}

To ensure that nonspecific binding was minimal, we performed control experiments on striatal tissue using sense strands for c-fos, preprotachykinin and preproenkephalin mRNA. There was no binding of the sense probes. Furthermore, we examined whether the preprotachykinin and preproenkephalin antisense probes labelled separate cells within the $\mathrm{CPu}$ by performing dual in situ hybridization using ${ }^{35} \mathrm{~S}-\mathrm{UTP}$ - and ${ }^{35}$ S-CTP-labelled preprotachykinin and digoxigenin-UTP-labelled preproenkephalin. We examined the same regions of the $\mathrm{CPu}$ as in the rest of the study. There were very few cells that were positive for both preproenkephalin and preprotachykinin mRNA in the $\mathrm{CPu}$ [101 of $2154 \mathrm{ENK}+$ cells were also SP+ (4.7\%); 101 out of $2284 \mathrm{SP}+$ cells were also $\mathrm{ENK}+(4.4 \%)$ ], confirming previous reports that, based on mRNA expression, these two cell populations in the $\mathrm{CPu}$ are almost completely segregated (Gerfen et al., 1988).

\section{Statistical analysis}

To investigate whether there was a difference in locomotor behaviour (beam breaks) during the pretreatment phase, a mixed two-way ANOVA was conducted (Dose, two levels; Day, seven levels).

The results from the challenge test were analysed by making two sets of comparisons. (i) To determine whether a particular treatment enhanced locomotor behaviour (number of beam breaks) or c-fos mRNA expression above baseline, data were normalized by subtracting the mean of the saline challenged groups from the value for each individual subject, and then a one-sample $t$-test was used to determine whether group means were significantly different from zero. The cocaine- and saline-pretreated groups that received a saline challenge injection did not differ on any of the measurements examined, so they were combined. (ii) To determine whether cocaine-induced locomotor behaviour or c-fos mRNA expression varied as a function of pretreatment and/or dose, two-way ANOvAs (Pretreatment, two levels; Dose, four levels) were conducted, followed by Fisher's PLSD tests for pairwise comparisons. For all comparisons $\alpha<0.05$.

In addition, we examined the relationship between c-fos expression in the STN and locomotor behaviour on the day of the challenge by calculating correlation coefficients, followed by Fisher's exact tests. 


\section{Results}

\section{Cocaine-induced psychomotor activity}

The insert in the top panel of Fig. 1 shows the behavioural results from the pretreatment phase of the experiment. ANOVA revealed a significant interaction between Day and Dose $\left(F_{6,483}=5.64, P<0.0001\right)$, which resulted from the increasing behavioural response produced by cocaine across pretreatment days (i.e. sensitization).

The top panel of Fig. 1 shows the behavioural results from the challenge injection administered 3 weeks after the final (7th) pre-

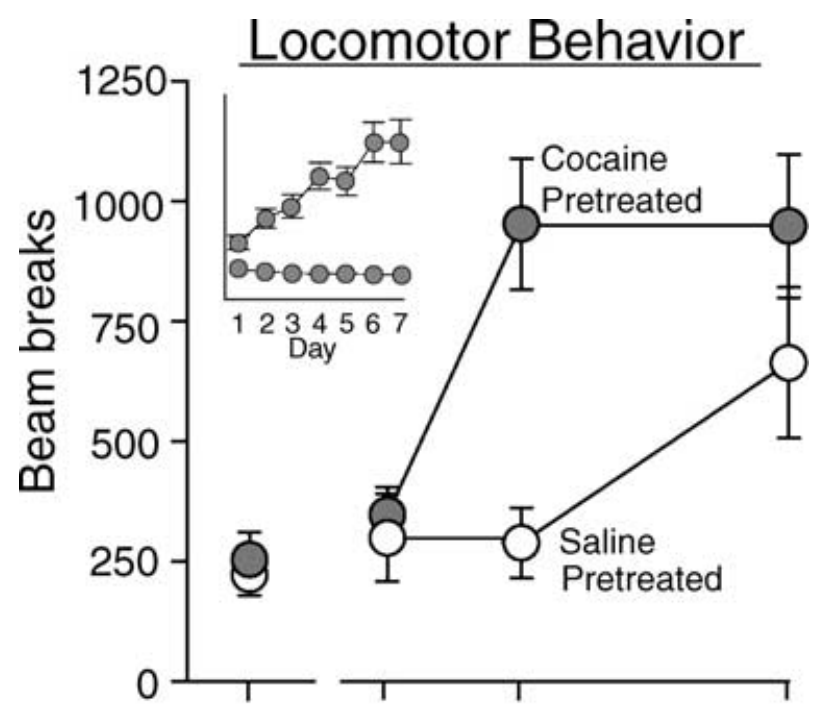

\section{STN c-fos expression}

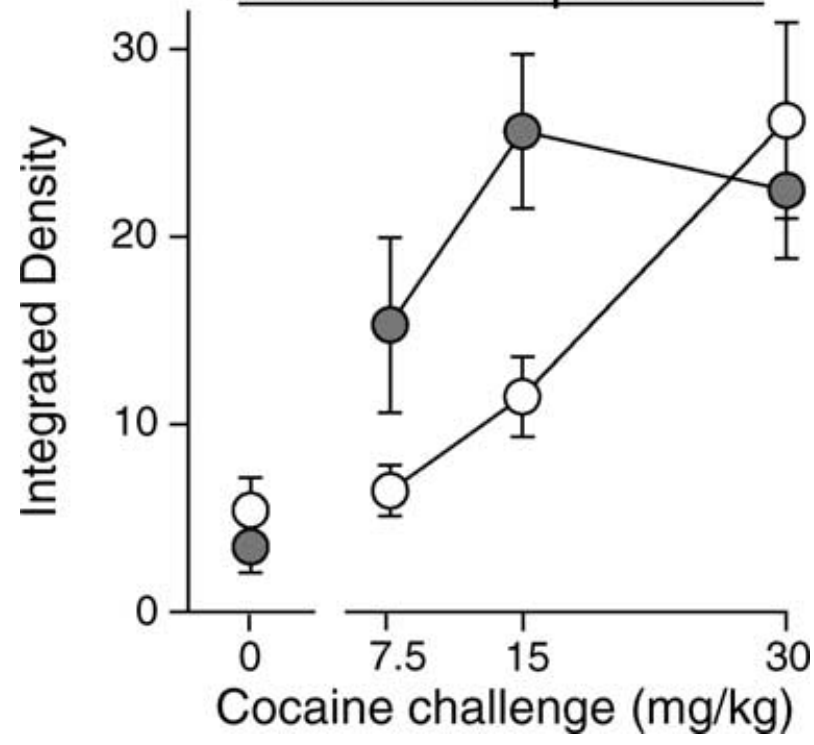

FIG. 1. Cocaine-induced psychomotor activation (beam breaks) and c-fos mRNA expression in the STN. Beam breaks were summed across the $45 \mathrm{~min}$ following saline or cocaine treatment. (Insert, top panel) The mean $( \pm$ SEM) number beam breaks produced by saline or cocaine $(15 \mathrm{mg} / \mathrm{kg})$ during the 7 days of pretreatment. The open circles represent the group that was pretreated with saline, and the closed circles represent the group that was pretreated with cocaine. (Top panel) The mean $( \pm$ SEM) number of beam breaks produced by a challenge injection of saline or of $7.5,15$ or $30 \mathrm{mg} / \mathrm{kg}$ of cocaine in rats pretreated with saline or cocaine. (Bottom panel) The expression of c-fos mRNA in the STN produced by a challenge injection of saline or of 7.5, 15 or $30 \mathrm{mg} / \mathrm{kg}$ of cocaine in rats pretreated with saline or cocaine, as indicated by analysis of relative integrated optical density values (arbitrary units). treatment injection. Saline-pretreated rats showed a significantly greater locomotor response to an injection of $30 \mathrm{mg} / \mathrm{kg}$ of cocaine, relative to baseline $(P<0.04)$, but none of the other doses produced a significant effect in saline-pretreated rats. In contrast, cocaine-pretreated rats that received either a 15 or $30 \mathrm{mg} / \mathrm{kg}$ cocaine challenge injection showed a significantly greater locomotor response than baseline $(P<0.012)$. Furthermore, there was an interaction between Dose and Pretreatment $\left(F_{3,64}=3.73, P<0.017\right)$, which was because cocaine pretreatment produced a shift to the left in the dose-effect function for psychomotor activity. The effect of cocaine pretreatment was most pronounced and reached statistical significance when a challenge dose of $15 \mathrm{mg} / \mathrm{kg}$ was given $(P<0.02)$. Figure 2 shows the time course of the behavioural response to the challenge injection.

\section{Cocaine-induced $c$-fos expression in the STN}

The bottom panel of Fig. 1 shows the dose-effect curve for cocaineinduced c-fos mRNA expression (integrated density) in the STN as a function of pretreatment condition. Animals pretreated with saline and given a 15 or $30 \mathrm{mg} / \mathrm{kg}$ cocaine challenge injection showed significantly enhanced levels of c-fos expression in the STN, compared to baseline $(P<0.026)$, but the effect of $7.5 \mathrm{mg} / \mathrm{kg}$ was not statistically significant. In contrast, animals pretreated with cocaine and challenged with either $7.5,15$ or $30 \mathrm{mg} / \mathrm{kg}$ of cocaine all showed a significant increase in c-fos expression in the STN, relative to baseline $(P<0.032)$. ANOVA revealed a significant Dose $\times$ Pretreatment interaction $\left(F_{3,64}=2.94, P<0.04\right)$. Thus, similar to the psychomotor activating response, cocaine pretreatment produced a shift to the left in the dose-effect function for cocaine-induced c-fos expression in the STN. This effect of cocaine pretreatment was most pronounced and reached statistical significance when a challenge dose of $15 \mathrm{mg} / \mathrm{kg}$ of

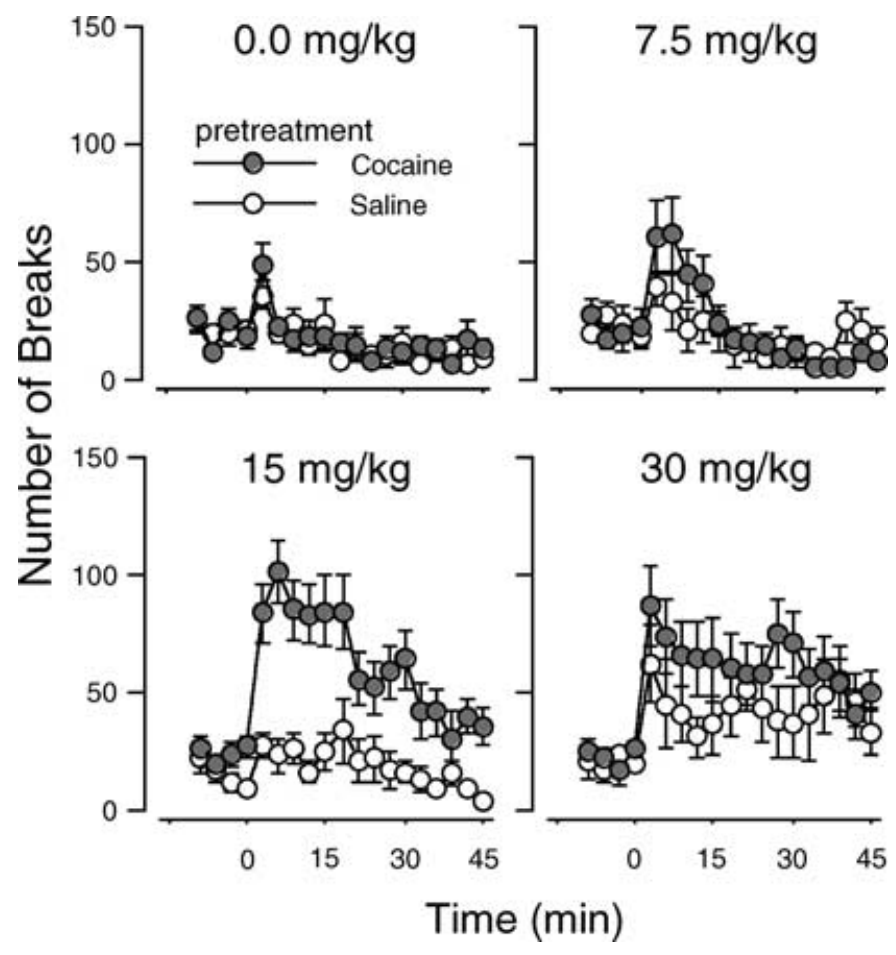

FIG. 2. The mean ( \pm SEM) number of beam breaks over time (3-min intervals) produced by a challenge injection of saline or of $7.5,15$ or $30 \mathrm{mg} / \mathrm{kg}$ of cocaine in rats pretreated with saline or cocaine. Injections were given at time point 0 . The open circles represent the group that had been pretreated with saline and the closed circles represent the group that had been pretreated with cocaine. 
cocaine was given $(P<0.02)$, again similar to the effect of cocaine pretreatment on psychomotor activity (see above).

Given the similarity of the dose-effect functions for cocaineinduced c-fos expression in the STN and locomotor activity, correlations between these variables were examined. When all animals were included in the analysis and plotted individually, there was a significant correlation between c-fos expression in the STN and the number of beam breaks ( $r=0.66, P<0.0001$; top panel of Fig. 3). Importantly, the correlation was greatest for those treatments that produced robust cocaine-induced behavioural effects. Thus, correlations between beam breaks and c-fos induction in the STN was greatest for animals receiving 15 or $30 \mathrm{mg} / \mathrm{kg}$ of cocaine following cocaine pretreatment ( $r=0.592$ and 0.627 , respectively) or $30 \mathrm{mg} / \mathrm{kg}$ of cocaine following saline pretreatment $(r=0.555$; data not shown). When the correlation analysis was conducted on the group means for c-fos expression in the STN and psychomotor activity, the correlation between these two measures was even greater $(r=0.89, P<0.02$; bottom panel of Fig. 3$)$.

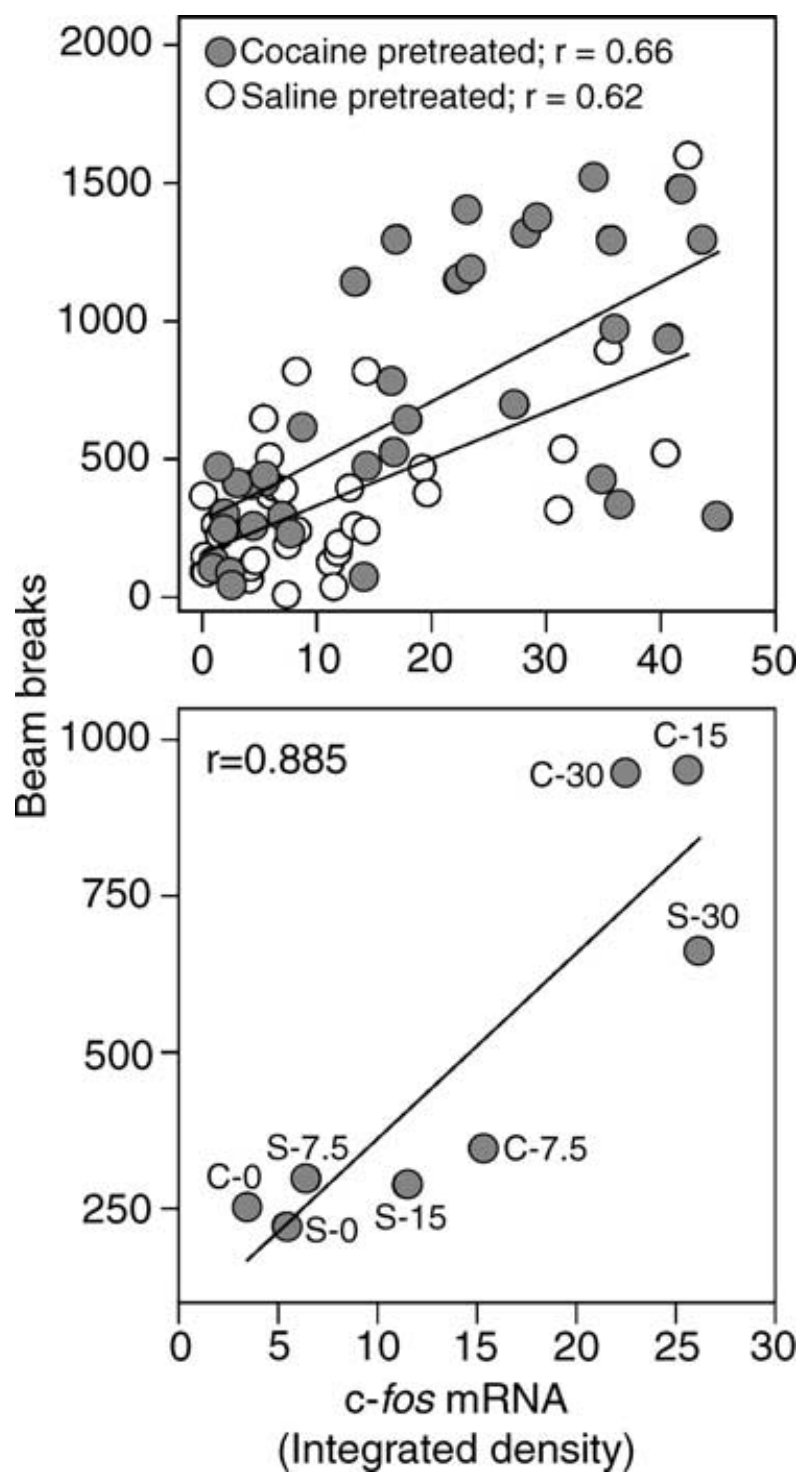

FIG. 3. Association between cocaine-induced psychomotor activation ( $y$-axis; beam breaks) and c-fos expression in the STN ( $x$-axis) when individual animals are plotted separately (top panel), and when group means are plotted separately (bottom panel). Abbreviations: r, correlation coefficient; S, saline pretreated; C, cocaine pretreated; $0,7.5,15$ or 30 , challenge dose of cocaine $(\mathrm{mg} / \mathrm{kg})$.

\section{Cocaine-induced c-fos expression in the $\mathrm{CPu}$}

The top panel of Fig. 4 shows the number of c-fos + cells in the $\mathrm{CPu}$ as a function of pretreatment condition and challenge dose. All doses of cocaine, irrespective of pretreatment, increased the number of c-fos + cells in the $\mathrm{CPu}$ relative to baseline $(P<0.008)$. Higher doses of
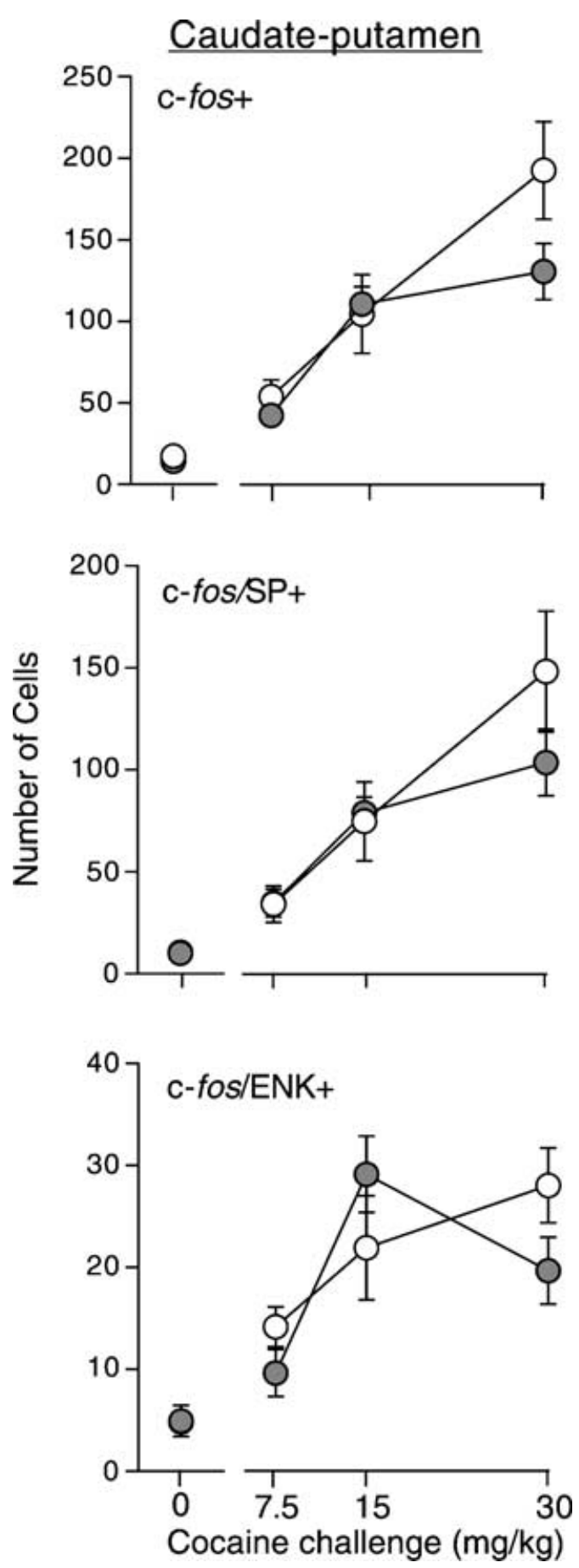

FIG. 4. Expression of $\mathrm{c}$-fos mRNA in the $\mathrm{CPu}$ of rats given saline or $7.5,15$ or $30 \mathrm{mg} / \mathrm{kg}$ of cocaine following pretreatment with saline or cocaine. (A) The mean $( \pm$ SEM) number of cells positive for c-fos mRNA as a function of dose and pretreatment. (B) The mean $( \pm$ SEM) number of cells positive for c-fos mRNA that were also positive for preprotachykinin mRNA ( $\mathrm{SP}+)$ as a function of dose and pretreatment. (C) The mean ( \pm SEM) number of cells positive for cfos mRNA that were also positive for preproenkephalin mRNA $(\mathrm{ENK}+)$ as a function of dose and pretreatment. 
cocaine increased the number of c-fos + cells in the $\mathrm{CPu}$ to a greater extent than lower doses (effect of Dose, $F_{3,65}=36.452, P<0.0001$ ), but there was no effect of Pretreatment $\left(F_{1,65}=2.74, P=0.1\right)$ and no Dose $\times$ Pretreatment interaction $\left(F_{3,65}=2.04, P=0.117\right)$.

The middle panel of Fig. 4 shows the number of $\mathrm{SP}+$ cells that were also positive for $\mathrm{c}-$ fos $(\mathrm{SP} / \mathrm{c}-f o s+)$ in the $\mathrm{CPu}$ as a function of treatment condition and challenge dose. Irrespective of pretreatment condition, all doses of cocaine increased the number of SP/c-fos + cells $(P<0.03)$. Higher doses increased the number of SP/c-fos + cells to a greater extent than lower doses $\left(F_{3,64}=27.094, P<0.0001\right)$, but there was no effect of Pretreatment $\left(F_{1,64}=1.058, P=0.308\right)$ and no Dose $\times$ Pretreatment interaction $\left(F_{3,64}=1.39, P=0.253\right)$.

The bottom panel of Fig. 4 shows the number of ENK+ cells that were also c-fos $+(\mathrm{ENK} / \mathrm{c}-f o s+)$ in the $\mathrm{CPu}$ as a function of pretreatment condition and challenge dose. Other than the group pretreated with cocaine and given a $7.5-\mathrm{mg} / \mathrm{kg}$ challenge, all groups showed an increase in the number of ENK/c-fos + cells relative to baseline. Higher doses increased the number of ENK/c-fos + cells compared to lower doses $\left(F_{3,64}=19.312, P<0.0001\right)$, but there was no effect of Pretreatment $\left(F_{1,64}=0.392, P=0.5337\right)$ and no Dose $\times$ Pretreatment interaction $\left(F_{3,64}=2.313, P=0.0844\right)$.

\section{Discussion}

We reported previously that conditions which enhance the ability of amphetamine and cocaine to produce psychomotor activation also increase their ability to induce c-fos expression in the STN (Uslaner et al., 2001b; Ostrander et al., 2003; Uslaner et al., 2003). We hypothesized therefore that the ability of these drugs to engage the STN may be important for their ability to produce robust psychomotor activation. This hypothesis was tested here by employing a cocaine pretreatment regimen that enhances the ability of a cocaine challenge to produce psychomotor activation (i.e. behavioural sensitization). We predicted that pretreatment with cocaine would also enhance its ability to induce c-fos expression in the STN. It did. Furthermore, given that $\mathrm{ENK}+$ cells in the CPu influence the STN via the indirect pathway, we predicted that repeated treatment with cocaine would enhance its ability to induce c-fos expression in ENK+ cells. It did not. Each of these findings will be discussed in turn.

\section{The relationship between psychomotor activation and engagement of the STN}

The present findings clearly support the idea that engaging the STN may be important for the psychomotor activating effects of stimulant drugs. First, similar to our findings with a single injection of amphetamine (Uslaner et al., 2003), cocaine produced a dose-dependent increase in c-fos mRNA expression in the STN that was accompanied by a dose-dependent increase in psychomotor activation. Second, cocaine pretreatment produced a shift to the left in the dose-effect function for cocaine-induced c-fos mRNA expression in the STN that was very similar to the shift in the dose-effect function for psychomotor activation. Pretreatment with cocaine enhanced the ability of the $15 \mathrm{mg} / \mathrm{kg}$ cocaine challenge to induce c-fos mRNA expression in the STN and to produce psychomotor activation, relative to pretreatment with saline. The $30 \mathrm{mg} / \mathrm{kg}$ challenge of cocaine induced robust c-fos expression in the STN and robust psychomotor activation, regardless of the animal's drug history. These results extend previous findings from our laboratory demonstrating enhanced amphetamine-induced cfos mRNA expression in the STN as a function of prior drug experience (Ostrander et al., 2003). Third, there was a positive correlation between cocaine-induced c-fos mRNA expression in the STN and psychomotor activation.
The role of the STN in stimulant-induced psychomotor activation has not received much attention until quite recently. There is, however, increasing evidence that it is involved. For example, it has been reported that acute injections of either methamphetamine or cocaine increases glucose utilization in the STN (Porrino et al., 1988; Pontieri et al., 1990), and acute amphetamine administration increases c-fos expression and cell firing in the STN (Ishida et al., 1998; Olds et al., 1998, 1999). In addition, bilateral STN lesions attenuate the ability of a single acute administration of cocaine to induce psychomotor activation (Baunez et al., 2002). Thus, the available literature, along with the results reported here, suggests that the STN plays an important role in mediating the psychomotor activating effects of stimulant drugs.

The mechanism(s) by which the STN influences the ability of stimulant drugs to produce psychomotor activation is unknown. However, glutamatergic projections from the STN to the ventral tegmental area (VTA) and the substantia nigra pars compacta $(\mathrm{SNc})$ may be involved (Kita \& Kitai, 1987; Groenewegen \& Berendse, 1990). Stimulation of the STN enhances cell firing in midbrain dopamine neurons (Hammond et al., 1978; Smith \& Grace, 1992), presumably engaging mesolimbic and nigrostriatal circuitry and inducing dopamine release in the striatum (Bruet et al., 2001). Indeed, glutamatergic agonists infused onto the STN induce Fos-immunoreactivity in the striatum and produce motor activation (Kearney \& Albin, 2000). Importantly then, glutamate and dopamine are known to be critical for stimulant-induced psychomotor activation. Systemically administered glutamate or dopamine antagonists (Maj et al., 1972; Schlechter \& Butcher, 1972; Karler et al., 1989; Karler et al., 1990), or lesions of dopamine projections to the striatum (Creese \& Iversen, 1974; Kelly et al., 1975; Kelly \& Iversen, 1976), block the psychomotor activating effects of both amphetamine and cocaine. Thus, by engaging mesolimbic and nigrostriatal circuitry, and thereby enhancing dopamine release in the striatum, engagement of the STN may potentiate stimulant-induced psychomotor activation. Of course, STN projections to other brain regions thought to be involved in stimulant-induced psychomotor activation, such as the globus pallidus (Kita \& Kitai, 1987; Groenewegen \& Berendse, 1990) and the striatum (Kita \& Kitai, 1987; Parent \& Smith, 1987), may also be important.

\section{The relationship between stimulant-induced engagement of the STN and ENK+ cells in the CPU}

Given that ENK+ cells are thought to influence the STN via the indirect pathway (Albin et al., 1989), we had hypothesized that engaging $\mathrm{ENK}+$ cells in the $\mathrm{CPu}$ would be important for the ability of stimulant drugs to engage the STN. However, our current findings suggest that the ability of psychostimulant drugs to engage the indirect pathway (at least as indicated by c-fos mRNA expression in ENK+ cells) is not necessary to induce c-fos in the STN. Pretreatment with cocaine enhanced the ability of a $15-\mathrm{mg} / \mathrm{kg}$ challenge of cocaine to induce c-fos in the STN, but had no effect on the ability of cocaine to engage ENK + cells. Others have also reported that repeated treatment with stimulant drugs does not enhance their ability to induce c-fos or Fos-immunoreactivity in ENK+ cells (Jaber et al., 1995; Moratalla et al., 1996; Canales \& Graybiel, 2000). In addition, we have previously found that a high dose of amphetamine $(10 \mathrm{mg} / \mathrm{kg})$ induces robust c-fos mRNA expression in the STN but does not induce c-fos in very many ENK+ cells (Uslaner et al., 2003). Moreover, lesions of the globus pallidus, which prevent ENK+ cells from influencing the STN via the indirect pathway, do not dramatically alter the ability of amphetamine to increase neuronal firing in the STN (Olds et al., 1998).

Of course, there are a variety of other inputs that could be important for the ability of cocaine to engage the STN. The SNc and VTA send dopaminergic projections to the STN (Campbell et al., 1985; Canteras 
et al., 1990; Hassani et al., 1997), and dopamine agonists enhance neural activity (Mintz et al., 1986; Kreiss et al., 1996, 1997; Ni et al., 2001) and c-fos expression in the STN (Ruskin \& Marshall, 1995; Svenningsson \& Le Moine, 2002). In addition, the STN receives efferents from the prefrontal cortex (Canteras et al., 1990), and cortical stimulation enhances neuronal firing (Maurice et al., 1998) and c-fos expression in the STN (Sgambato et al., 1997). The involvement of these projections seems especially interesting, given the hypothesized involvement of these structures in the psychomotor activating effects of stimulant drugs (Eichler \& Antelman, 1979; Robinson et al., 1985; Vezina \& Stewart, 1990; Banks \& Gratton, 1995; Pierce \& Kalivas, 1997).

\section{Conclusions}

The current findings suggest that the STN contributes to the psychomotor activating effects of cocaine. The ability of cocaine to induce cfos in the STN was enhanced by doses and treatment regimens that produced robust psychomotor activation. Furthermore, there was a significant correlation between drug-induced c-fos expression in the STN and psychomotor activation. In addition, given that the expression of behavioural sensitization was observed at challenge doses where there was a significant effect of pretreatment on cocaine-induced c-fos in the STN, the role of the STN in sensitization also merits consideration. In this regard, it is worth noting that stimulation of the STN produces LTP in dopamine-containing neurons in the SNc (Overton et al., 1999), which may contribute to the sensitization process (Wolf, 1998). Finally, given the possible relationship between sensitization and addiction (Robinson \& Berridge, 1993), future consideration of the role of the STN in the reinforcing effects of psychostimulants seems warranted. Indeed, the STN has also been implicated recently in the incentive motivational effects of cocaine (Baunez et al., 2002).

\section{Acknowledgements}

This research was supported by a NIDA grant to T.E.R. (R37 DA04294). T.E.R. was also supported by a Senior Research Scientist Award from NIDA (K05 DA00473). We thank Piotr Myc for his assistance in conducting these experiments and Stanley Watson and Huda Akil for generously providing the riboprobes.

\section{Abbreviations}

$\mathrm{CPu}$, caudate-putamen; ENK/c-fos +, ENK+ cells that were also c-fos+; $\mathrm{ENK}+$ cells, enkephalin-containing cells in the $\mathrm{CPu}$; SP, substance $\mathrm{P} ; \mathrm{SP} / \mathrm{c}-$ fos,$+ \mathrm{SP}+$ cells that were also positive for c-fos; STN, subthalamic nucleus.

\section{References}

Albin, R.L., Young, A.B. \& Penney, J.B. (1989) The functional anatomy of basal ganglia disorders. Trends Neurosci., 12, 366-375.

Badiani, A., Oates, M.M., Day, H.E., Watson, S.J., Akil, H. \& Robinson, T.E. (1998) Amphetamine-induced behavior, dopamine release, and c-fos mRNA expression: modulation by environmental novelty. J. Neurosci., 18, 1057910593.

Badiani, A., Oates, M.M., Day, H.E., Watson, S.J., Akil, H. \& Robinson, T.E. (1999) Environmental modulation of amphetamine-induced c-fos expression in D1 versus D2 striatal neurons. Behav. Brain Res., 103, 203-209.

Banks, K.E. \& Gratton, A. (1995) Possible involvement of medial prefrontal cortex in amphetamine-induced sensitization of mesolimbic dopamine function. Eur. J. Pharmacol., 282, 157-167.

Baunez, C., Cador, M., Dias, C., Robbins, T.W. \& Amalric, M. (2002) Bilateral lesions of the subthalamic nucleus increase motivation for food, but reduce the incentive motivation produced by drugs of abuse. FENS Forum Abstr., 42, 115.

Browman, K.E., Badiani, A. \& Robinson, T.E. (1998) Modulatory effect of environmental stimuli on the susceptibility to amphetamine sensitization: a dose-effect study in rats. J. Pharmacol. Exp. Ther., 287, 1007-1014.
Bruet, N., Windels, F., Bertrand, A., Feuerstein, C., Poupard, A. \& Savasta, M. (2001) High frequency stimulation of the subthalamic nucleus increases the extracellular contents of striatal dopamine in normal and partially dopaminergic denervated rats. J. Neuropathol. Exp. Neurol., 60, 15-24.

Campbell, G.A., Eckardt, M.J. \& Weight, F.F. (1985) Dopaminergic mechanisms in subthalamic nucleus of rat: analysis using horseradish peroxidase and microiontophoresis. Brain Res., 333, 261-270.

Canales, J.J. \& Graybiel, A.M. (2000) A measure of striatal function predicts motor stereotypy. Nature Neurosci., 3, 377-383.

Canteras, N.S., Shammah-Lagnado, S.J., Silva, B.A. \& Ricardo, J.A. (1990) Afferent connections of the subthalamic nucleus: a combined retrograde and anterograde horseradish peroxidase study in the rat. Brain Res., 513, $43-59$.

Creese, I. \& Iversen, S.D. (1974) The role of forebrain dopamine systems in amphetamine induced stereotyped behavior in the rat. Psychopharmacologia, 39, 345-357.

Crombag, H.S., Badiani, A., Chan, J., Dell'Orco, J., Dineen, S.P. \& Robinson, T.E. (2001) The ability of environmental context to facilitate psychomotor sensitization to amphetamine can be dissociated from its effect on acute drug responsiveness and on conditioned responding. Neuropsychopharmacology, 24, 680-690.

Cullinan, W.E., Herman, J.P., Battaglia, D.F., Akil, H. \& Watson, S.J. (1995) Pattern and time course of immediate early gene expression in rat brain following acute stress. Neuroscience, 64, 477-505.

Curran, E.J. \& Watson, S.J. Jr (1995) Dopamine receptor mRNA expression patterns by opioid peptide cells in the nucleus accumbens of the rat: a double in situ hybridization study. J. Comp. Neurol., 361, 57-76.

Day, H.E., Badiani, A., Uslaner, J.M., Oates, M.M., Vittoz, N.M., Robinson, T.E., Watson, S.J. Jr \& Akil, H. (2001) Environmental novelty differentially affects c-fos mRNA expression induced by amphetamine or cocaine in subregions of the bed nucleus of the stria terminalis and amygdala. J. Neurosci., 21, 732-740.

Eichler, A.J. \& Antelman, S.M. (1979) Sensitization to amphetamine and stress may involve nucleus accumbens and medial frontal cortex. Brain Res., 176, $412-416$.

Gerfen, C.R., Young, W.S. \& d. (1988) Distribution of striatonigral and striatopallidal peptidergic neurons in both patch and matrix compartments: an in situ hybridization histochemistry and fluorescent retrograde tracing study. Brain Res., 460, 161-167.

Groenewegen, H.J. \& Berendse, H.W. (1990) Connections of the subthalamic nucleus with ventral striatopallidal parts of the basal ganglia in the rat. J. Comp. Neurol., 294, 607-622.

Hammond, C., Deniau, J.M., Rizk, A. \& Feger, J. (1978) Electrophysiological demonstration of an excitatory subthalamonigral pathway in the rat. Brain Res., 151, 235-244.

Hassani, O.K., Francois, C., Yelnik, J. \& Feger, J. (1997) Evidence for a dopaminergic innervation of the subthalamic nucleus in the rat. Brain Res., 749, 88-94.

Ishida, Y., Todaka, K., Kuwahara, I., Ishizuka, Y., Hashiguchi, H., Nishimori, T. \& Mitsuyama, Y. (1998) Methamphetamine induces fos expression in the striatum and the substantia nigra pars reticulata in a rat model of Parkinson's disease. Brain Res., 809, 107-114.

Jaber, M., Cador, M., Dumartin, B., Normand, E., Stinus, L. \& Bloch, B. (1995) Acute and chronic amphetamine treatments differently regulate neuropeptide messenger RNA levels and Fos immunoreactivity in rat striatal neurons. Neuroscience, 65, 1041-1050.

Karler, R., Calder, L.D., Chaudhry, I.A. \& Turkanis, S.A. (1989) Blockade of 'reverse tolerance' to cocaine and amphetamine by MK-801. Life Sci., 45, 599-606.

Karler, R., Chaudhry, I.A., Calder, L.D. \& Turkanis, S.A. (1990) Amphetamine behavioral sensitization and the excitatory amino acids. Brain Res., 537, 76-82.

Kearney, J.A. \& Albin, R.L. (2000) Intrasubthalamic nucleus metabotropic glutamate receptor activation: a behavioral, Fos immunohistochemical and $\left[{ }^{14} \mathrm{C}\right] 2$-deoxyglucose autoradiographic study. Neuroscience, 95, 409-416.

Kelly, P.H. \& Iversen, S.D. (1976) Selective 6OHDA-induced destruction of mesolimbic dopamine neurons: abolition of psychostimulant-induced locomotor activity in rats. Eur. J. Pharmacol., 40, 45-56.

Kelly, P.H., Seviour, P.W. \& Iversen, S.D. (1975) Amphetamine and apomorphine responses in the rat following 6-OHDA lesions of the nucleus accumbens septi and corpus striatum. Brain Res., 94, 507-522.

Kita, H. \& Kitai, S.T. (1987) Efferent projections of the subthalamic nucleus in the rat: light and electron microscopic analysis with the PHA-L method. J. Comp. Neurol., 260, 435-452. 
Kreiss, D.S., Anderson, L.A. \& Walters, J.R. (1996) Apomorphine and dopamine D (1) receptor agonists increase the firing rates of subthalamic nucleus neurons. Neuroscience, 72, 863-876.

Kreiss, D.S., Mastropietro, C.W., Rawji, S.S. \& Walters, J.R. (1997) The response of subthalamic nucleus neurons to dopamine receptor stimulation in a rodent model of Parkinson's disease. J. Neurosci., 17, 6807-6819.

Maj, J., Sowinska, H., Kapturkiewicz, Z. \& Sarnak, J. (1972) The effect of 1dopa and $(+)$-amphetamine on the locomotor activity after pimozide and phenoxybenzamine. J. Pharm. Pharmacol., 24, 412-414.

Maurice, N., Deniau, J.M., Glowinski, J. \& Thierry, A.M. (1998) Relationships between the prefrontal cortex and the basal ganglia in the rat: physiology of the corticosubthalamic circuits. J. Neurosci., 18, 9539-9546.

Mintz, I., Hammond, C. \& Feger, J. (1986) Excitatory effect of iontophoretically applied dopamine on identified neurons of the rat subthalamic nucleus. Brain Res., 375, 172-175.

Moratalla, R., Elibol, B., Vallejo, M. \& Graybiel, A.M. (1996) Network-level changes in expression of inducible Fos-Jun proteins in the striatum during chronic cocaine treatment and withdrawal. Neuron, 17, 147-156.

Ni, Z., Gao, D., Bouali-Benazzouz, R., Benabid, A.L. \& Benazzouz, A. (2001) Effect of microiontophoretic application of dopamine on subthalamic nucleus neuronal activity in normal rats and in rats with unilateral lesion of the nigrostriatal pathway. Eur. J. Neurosci., 14, 373-381.

Olds, M.E., Jacques, D.B. \& Kopyov, O. (1998) Globus pallidus lesions depress the excitatory responses to apomorphine but not amphetamine in the subthalamic nucleus of the behaving rat with a 6-OHDA nigra lesion. Brain Res., 812, 50-64.

Olds, M.E., Jacques, D.B. \& Kopyov, O. (1999) Subthalamic responses to amphetamine and apomorphine in the behaving rat with a unilateral 6-OHDA lesion in the substantia nigra. Synapse, 34, 228-240.

Ostrander, M.M., Badiani, A., Day, H.E.W., Norton, C., Watson, S.E., Akil, H. \& Robinson, T.E. (2003) Environmental context and past drug history modulate amphetamine-induced c-fos mRNA expression in the basal ganglia, central extended amygdala, and associated limbic forebrain. Neuroscience, in press.

Overton, P.G., Richards, C.D., Berry, M.S. \& Clark, D. (1999) Long-term potentiation at excitatory amino acid synapses on midbrain dopamine neurons. Neuroreport, 10, 221-226.

Parent, A. \& Smith, Y. (1987) Organization of efferent projections of the subthalamic nucleus in the squirrel monkey as revealed by retrograde labeling methods. Brain Res., 436, 296-310.

Pierce, R.C. \& Kalivas, P.W. (1997) A circuitry model of the expression of behavioral sensitization to amphetamine-like psychostimulants. Brain Res. Brain Res. Rev., 25, 192-216.
Pontieri, F.E., Crane, A.M., Seiden, L.S., Kleven, M.S. \& Porrino, L.J. (1990) Metabolic mapping of the effects of intravenous methamphetamine administration in freely moving rats. Psychopharmacology (Berl.), 102, 175-182.

Porrino, L.J., Domer, F.R., Crane, A.M. \& Sokoloff, L. (1988) Selective alterations in cerebral metabolism within the mesocorticolimbic dopaminergic system produced by acute cocaine administration in rats. Neuropsychopharmacology, 1, 109-118.

Robinson, T.E., Becker, J.B., Moore, C.J., Castaneda, E. \& Mittleman, G. (1985) Enduring enhancement in frontal cortex dopamine utilization in an animal model of amphetamine psychosis. Brain Res., 343, 374-377.

Robinson, T.E. \& Berridge, K.C. (1993) The neural basis of drug craving: an incentive-sensitization theory of addiction. Brain Res. Brain Res. Rev., 18, 247-291.

Ruskin, D.N. \& Marshall, J.F. (1995) D1 dopamine receptors influence Fos immunoreactivity in the globus pallidus and subthalamic nucleus of intact and nigrostriatal-lesioned rats. Brain Res., 703, 156-164.

Schlechter, J.M. \& Butcher, L.L. (1972) Blockade by pimozide of (+)-amphetamine-induced hyperkinesia in mice. J. Pharm. Pharmacol., 24, 408-409.

Sgambato, V., Abo, V., Rogard, M., Besson, M.J. \& Deniau, J.M. (1997) Effect of electrical stimulation of the cerebral cortex on the expression of the Fos protein in the basal ganglia. Neuroscience, 81, 93-112.

Smith, I.D. \& Grace, A.A. (1992) Role of the subthalamic nucleus in the regulation of nigral dopamine neuron activity. Synapse, 12, 287-303.

Svenningsson, P. \& Le Moine, C. (2002) Dopamine D1/5 receptor stimulation induces c-fos expression in the subthalamic nucleus: possible involvement of local D5 receptors. Eur. J. Neurosci., 15, 133-142.

Uslaner, J., Badiani, A., Day, H.E., Watson, S.J., Akil, H. \& Robinson, T.E. (2001a) Environmental context modulates the ability of cocaine and amphetamine to induce c-fos mRNA expression in the neocortex, caudate nucleus, and nucleus accumbens. Brain Res., 920, 106-116.

Uslaner, J., Badiani, A., Norton, C., Day, H., Watson, S., Akil, H. \& Robinson, T. (2001b) Amphetamine and cocaine induce different patterns of c-fos mRNA expression in the striatum and subthalamic nucleus depending on envrionmental cotext. Eur. J. Neurosci., 13, 1977-1983.

Uslaner, J.M., Norton, C.S., Watson, S.J., Akil, H. \& Robinson, T.E. (2003) Amphetamine-induced c-fos mRNA expression in the caudate-putamen and subthalamic nucleus: interactions between dose, environment, and neuronal phenotype. J. Neurochem., 85, 105-119.

Vezina, P. \& Stewart, J. (1990) Amphetamine administered to the ventral tegmental area but not to the nucleus accumbens sensitizes rats to systemic morphine: lack of conditioned effects. Brain Res., 516, 99-106.

Wolf, M.E. (1998) The role of excitatory amino acids in behavioral sensitization to psychomotor stimulants. Prog. Neurobiol., 54, 679-720. 